\title{
Casos e Working Papers Agências reguladoras e os limites de seus poder
}

Carla Winter Afonso*

\section{Introdução}

Este texto visa analisar o papel das agências reguladoras diante das limitações definidas na Constituição Federal de 1988. Inicialmente, será analisado o novo papel regulador do Estado no contexto econômico. Posteriormente, discutiremos as características específicas do modelo brasileiro, destacando principalmente a independência política e financeira das agências.

\section{O novo papel do Estado}

Camargo (1992) afirma que a história brasileira é marcada por movimentos pendulares, ora favorecendo o intervencionismo e a padronização de regras, ora privilegiando a autonomia dos atores econômicos e políticos. Esse movimento foi chamado de "sístole e diástole" por Golbery do Couto e Silva, figura importante do regime militar de 1964, pois o Estado brasileiro tende tanto à centralização quanto à descentralização. Em vários momentos age como interventor; em outros, delega esse poder à Federação ou ao mercado.

A crise de 1929 - caracterizada como a crise do capitalismo - provocou o surgimento de um ideal, segundo o qual o Estado era perfeitamente capaz de intervir na economia. Esse então novo ideal mundial foi marcado pela figura de Keynes, defensor da intervenção direta do Estado na geração de empregos e no fomento à economia. No Brasil, esse período foi caracterizado pela Revolução de 1930 e a Era Vargas. Para Camargo (1992), a partir dali, os movimentos de "sístoles e diástoles" se alternaram: um primeiro momento centralizador e autoritário (1930-45), um segundo momento federativo (1945-64) e um terceiro momento extremamente autoritário e centralizador (1964-85).

Podemos perceber que ao longo desse período, o Estado foi aumentando seu aparato, crescendo cada vez mais. A intervenção na economia e a criação das estatais foram características daqueles anos. Todos os questionamentos, do âmbito econômicos ao âmbito político, foram englobados pelo grande aparato estatal. O Estado foi o fomentador e o regulador da economia.

Todavia, na década de 1980, o governo brasileiro sofreu com o esgotamento do modelo intervencionista devido às altas despesas estatais geradas pelas suas grandes empresas públicas. O Estado brasileiro encontrava-se numa grande crise fiscal, além de arcar com uma elevada dívida externa, o que não mais permitia sustentar o modelo intervencionista. No contexto mundial, o modelo liberal começava a se fazer presente já desde da década de 1960, mas somente após a crise dos anos 1980 foi que o Estado brasileiro resolveu dar lugar a entidades privadas em setores exclusivamente estatais. Segundo esse novo modelo, o Estado daria lugar a entidades privadas no desenvolvimento do país, participando da Economia somente como agente regulador. Esse novo modelo foi chamado de modelo de regulação, desenvolvido inicialmente na Inglaterra e depois adaptado por vários outros países.

A partir dos anos 1990, com o presidente Fernando Henrique Cardoso, são adotadas medidas para tentar diminuir os gastos públicos. Essas medidas incluíam o ajuste fiscal, as privatizações e a reforma administrativa

* Pesquisadora vinculada ao Clube de Roma. Mestre em administração pública pela Escola Brasileira de Administração Pública e de Empresas da Fundação Getulio Vargas - EBAPE/FGV. Endereço: Praia de Botafogo 190 - sala 509 - Rio de Janeiro - RJ - Brasil - CEP 22253-900. E-mail: winter@fgvmail.br. 
do Estado. Nesse contexto, surgiu a discussão sobre um novo modelo de Estado, um modelo regulador. O Estado deixava de ser o interventor e abria mão desse papel em favor do setor privado; ou seja, o mercado seria o centro das decisões e o Estado deveria permanecer como regulador das relações econômicas. O Estado permitiu a privatização de vários setores, tentando diminuir gastos. Dentre esses setores estão o de energia elétrica, o de abastecimento de água, o de telecomunicações e o petrolífero.

Para regular as atividades, agora não mais exclusivas do Estado, foram criadas autarquias especiais, política e financeiramente independentes. Essas autarquias, criadas por lei, têm a função de disciplinar a atividade econômica em setores estratégicos do serviço público.

\section{0 modelo brasileiro e os limites de poder das agências}

O Estado dispõe de uma série de mecanismos para controle das atividades econômicas, dentre os quais, as agências independentes reguladoras. Atualmente, existem as seguintes agências, criadas pela União:

- Agência Nacional de Energia Elétrica (Aneel),

- Agência Nacional de Telecomunicações (Anatel);

- Agência Nacional de Transportes Terrestres (ANTT);

- Agência Nacional do Petróleo (ANP);

- Agência Nacional de Vigilância Sanitária (Anvisa);

- Agência Nacional de Águas (ANA); e

- Agência Nacional de Saúde Suplementar (ANS).

Cada agência disciplina as práticas de inserção e concorrência em seus respectivos setores. Elas cuidam de setores distintos, mas apresentam algumas características comuns, definidas pela legislação que as criou. Todas se caracterizam pela independência, pela especialização técnica e por terem uma função reguladora. Mais adiante, serão melhor definidas essas características e os tipos de limitações constitucionais percebidas.

As agências têm autonomia de decisão e não estão subordinadas hierarquicamente ao chefe do Poder Executivo. Este tem poder limitado, inclusive no que diz respeito à nomeação dos dirigentes da agência, pois apesar de indicá-los, essa indicação tem de ser aprovada pelo Senado. Além disso, a independência política da agência também é mantida através de mandatos estáveis, não coincidentes com os mandatos presidenciais; ou seja, os mandatos dos dirigentes atravessam governos diferentes, o que lhes confere certa independência. A independência financeira, por sua vez, é conseguida através da cobrança de uma taxa aos entes regulados de cada setor. Independência essa que, logicamente, não significa que esses entes estejam livres de sanções do Poder Judiciário.

Esse tópico relativo à independência pode gerar certas dúvidas com relação a sua constitucionalidade. Podemos alegar que a nomeação para esses cargos é inconstitucional, pois os dirigentes não são submetidos a concurso público, invalidando o mandato estável, o que defende Aragão (2002) . Essa questão foi levantada no Supremo Tribunal Federal (STF), que decidiu que tal ação não é procedente. De acordo com o ministro Vitor Nunes Leal, a ação não poderia ter procedência com base em argumento já utilizado em outro caso, uma vez que "a competência administrativa de prover cargos públicos admite configurações de investiduras outras, desde que expressamente definidas na lei criadora" (ARAGÃO, p. 32).

Com relação à característica de especialização, devemos ressaltar que a agência tem papel regulador, pois cabe a ela a edição de normas. Logo, deveria ser formada por pessoas também especializadas em direito. Nesse sentido, existe a necessidade de pessoal mais especializado em questões legais, uma vez que as agências têm poder quase legislativo. Encontra-se aí um dos grandes problemas de conceder o poder normativo, a falta de especialização dentro das Agências com relação a aspectos legais na edição de normas e regulamentos (ARAGÃO, 2002). 
Outra questão levantada é a própria legitimidade da agência: elas poderiam impor obrigações através de regulações, quando somente uma lei pode criar tais obrigações? A fonte de obrigação é sempre a lei; nunca o regulamento. Como podemos justificar tal fato? Outra dúvida que pode surgir é a seguinte: a agência assume uma função quase de Poder Legislativo; então, onde está a separação dos poderes? Essas questões são de extrema importância para o entendimento dos limites do poder das agências e sua constitucionalidade, sendo diversas vezes levantadas por juristas e questionadores do sistema normativo de poder das agências

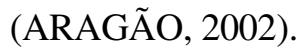

A Anatel e a ANP já são contempladas pelo texto constitucional, e estariam aptas a exercer a função normativa. A Constituição brasileira estabelece que as hipóteses normativas de atribuição de atribuição do Poder Legislativo ao Poder Executivo deve se restringir àquelas previamente delimitadas em seu texto (ARAGÃO, 2002). Conclui-se daí que, somente, essas duas agências teriam legalidade, seriam constitucionais. No entanto, como a situação de crise econômica é mais forte que esses questionamentos, as agências continuam a exercer funções normativas.

Uma das justificativas para o "superpoder" das agências pode ser o enfraquecimento do Estado, que não é mais capaz de regulamentar apenas pela lei. Nesse momento, surge uma regulamentação que tenta preencher esse vazio criado pela ineficiência do aparato estatal.

A criação das agências nos faz questionar o próprio sistema representativo brasileiro, que não mais consegue atender a todas as demandas da sociedade moderna (ARAGÃO, 2002). As agências tomaram o lugar do Congresso Nacional e do próprio presidente na tomada de importantes decisões para o desenvolvimento do país. Ao mesmo tempo, o Estado deixa de ter responsabilidades sobre setores cruciais, deixando de ser o produtor e o regulador dessa nova economia, eximindo-se de possível culpa por problemas futuros.

\section{Conclusão}

A crise do modelo intervencionista do Estado e a precariedade do sistema representativo brasileiro possibilitaram a atribuição de poderes normativos (quase legislativos) para as agências reguladoras. Ocorreu a ruptura de um modelo clássico - onde há clara separação entre as três esferas de poder - para o modelo do "Estado irresponsável", em que entidades independentes assumem funções quase legislativas.

As agências foram criadas no vazio deixado pelo Estado e sua criação foi justificada pela ocorrência de crises continuadas. Incapaz de manter o controle sobre os diversos setores da economia, o Estado abriu mão de parte desse poder já esvaziado, abrindo caminho para a criação de autarquias independentes que, então, assumiram funções antes exercidas pelo Poder Estatal. Não sendo mais possível a regulamentação somente através das leis existentes, as agências desenvolveram regulamentos independentes. Como não existem outros mecanismos de controle sendo desenvolvidos, as agências continuam aplicando estes regulamentos.

O Estado deve estar presente no controle da economia, ainda que exercendo um papel somente de supervisor e não mais de produtor. Um fato que deve ser relembrado quando estudamos o caso brasileiro é a vinculação ainda existente entre as agências e os ministérios, tornando necessário definir claramente o papel destes. Como o Estado pode ainda participar desse processo através dessa vinculação?

O Estado não pode permanecer fora do processo. Ele deve exercer algum tipo de influência sobre as agências, ao menos, como mantenedor de uma ordem democrática. A vinculação entre as agências e os ministérios deve ser bem definida para tentar evitar qualquer tipo de cooptação desses agentes independentes pelo mercado. $\mathrm{O}$ real Estado regulador não perde responsabilidade sobre as relações econômicas, mesmo que não detenha mais o monopólio. 


\section{Questões para debate}

1. Qual o interesse do Estado quando optou pela transferência do controle de certos setores cruciais da economia? E o interesse do Estado estaria em conformidade com os interesses de tais setores?

2. Por que as agências mantêm o poder normativo, apesar de não poderem legalmente editar leis?

3. Como as agências conseguem manter a independência política e financeira? Essa independência é positiva para a sociedade?

4. Por que questionaram a constitucionalidade dos mandatos dos dirigentes das agências? O que você pensa disso?

5. Qual a relação entre agências e ministérios no controle dos setores privatizados? Seria uma boa relação, motivadora de saltos de qualidade? 


\section{Referências}

ARAGÃO, Alexandre Santos de. As Agências Reguladoras Independentes e a Separação de Poderes: Uma Contribuição da Teoria dos Ordenamentos Setoriais. IN: Revista Diálogo Jurídico. Salvador: CAJ - Centro de Atualização Jurídica, n. ${ }^{13, ~ p . ~ 28, ~ a b r i l / m a i o, ~} 2002$.

CAMARGO, A. A federação acorrentada: nacionalismo desenvolvimentista e instabilidade democrática. México: Fundo de Cultura, 1992. 